\title{
Mixing Numbers and Letters: Collaboration Between Engineering and English to Improve Graduate Student Work
}

\author{
Craig Baltimore, Deborah Wilhelm, Mary Forte, and Pamalee Brady
}

\begin{abstract}
This paper will describe the issues and process of developing an introductory course in graduate writing and communication skills in conjunction with the industry of professional consulting engineering. The course was developed through a collaboration of English and engineering faculty and the collaboration is maintained in the teaching of the course. Innovative techniques incorporated into the course development include a four-pronged approach: 1) use of best practices for Writing in the Disciplines; 2) development of and focus on a multi-faceted collaborative model (Engineering and English, university and industry, students and faculty, industry and students); 3) teamteaching by engineering and English faculty members for the initial graduate research course; and 4) emphasis on the quality of the thesis project content in terms of the research itself, analysis and synthesis of that research, and effective communication of the results. Accountability and assessment of students' work includes development of the thesis project statement and presentation of their work to a body of their peers; presentations and evaluations by departmental faculty; and round table talks with industry. This system of accountability and assessment have shown marked improvement in the communication skill set often minimized in both undergraduate and graduate engineering education.
\end{abstract}

Index Terms - collaboration, course development, English, engineering, industry, thesis

\section{INTRODUCTION}

Three years ago the Department of Architectural Engineering (ARCE) at the California Polytechnic State University in San Luis Obispo (Cal Poly) began offering a Master's degree with emphasis in architectural and structural engineering. The masters program was designed to complement the existing undergraduate program and maintain a strong link with the profession of consulting engineering, giving the university an opportunity to create a unique program that would offer students the ability to meet the future professional requirement of licensure while gaining exposure to issues facing the professional consultant. The combination of licensure requirements and issues of the profession foregrounded the need to create a graduate-level course in communication, in which communication addresses both the academic (research and thesis) and the professional (e-mail, letter writing, research, and presentations) needs of the field. Writing that is clear, concise, correct, and effective in its transmission of information is crucial in both academia and the profession. The combination of writing and the profession gave birth to a natural collaboration of English and engineering faculty.

The need for improved communications among engineering students and working engineers is an age old issue and has been well documented. In 1937, C.W. Dunham [1] noted in the Journal of Engineering Education that in regards to English writing abilities, "Engineers are notoriously weak in mastering it." A 2004 survey by the National Committee on Writing found that of businesses who responded, participants indicated that PowerPoint and email had become "nearly universal" methods of communication, and that " $[\mathrm{m}]$ ore than half of all responding companies report that they 'frequently' or 'almost always' produce technical reports (59 percent), formal reports (62 percent), and memos and correspondence (70 percent)" [2] These same respondents reported that remediating writing deficiencies among their employees may cost up to $\$ 3.1$ billion dollars annually, in 2004 dollars. More recently, and focused specifically on engineering, IEEE Transactions on Professional Communication published a 2008 special issue, "Communication in Engineering Curricula." In the introductory essay to that issue, Paretti and McNair point out that "[e]ffectively integrating communication into engineering curricula $[\ldots]$ requires interdisciplinary collaboration," and they offer a challenge for future research that explores "theoretical and empirical models of integration that examine an array of partnerships between communications experts and engineering faculty" [3]. This paper is one such exploration.

The collaboration at Cal Poly had its seeds in a pedagogical conversation among faculty colleagues. Cal Poly offers faculty from all departments a quarterly workshop, WINGED (Writing in Generally Every Discipline), a series of meetings fostering interdisciplinary conversations among colleagues and providing practical strategies for improving students' critical thinking, reading, and-especially-students' writing skills. The series provides a variety of tools, many of which are particularly 
relevant to students preparing for graduate-level and professional communication: emphasizing the rhetorical purposes of different genres of writing, the importance of thesis writing as a contribution to the engineering field, the damage to an engineer's ethos from poor writing, and so on. As the ARCE Department began admitting its first graduate students, the WINGED series opened a conversation centered on an innovative pedagogical approach using a collaborative model and best classroom practices to improve students' writing and increase their chances of academic and professional success. Cal Poly's motto is, Learn by Doing, a hands-on approach to learning that is visible throughout the university community. For both faculty and students Learn by Doing informs pedagogical strategies across the campus, and in this case gave rise to a collaborative model of preparing new graduate students as academic and professional writers, a collaboration that is reflected in the course design and carried into the classroom, where both the English and engineering faculty teach the course and are invested in students' success as vital parts of the web of relationships among University, industry, and students.

\section{Guidance for Course Development}

The Department of Architectural Engineering (ARCE) identifies its first client as the profession of consulting structural engineering (hereafter referred to as industry). As the first client industry is consulted for curriculum development and assessment, a consultation that occurs in many forms, such as advisory boards, surveys, and forums. In addition $50 \%$ of the faculty in ARCE have direct and extensive industry experience, so maintaining industry relationships is an important concern of administration, faculty, and students.

Input from industry indicated an overwhelming need to improve the writing and communication skills of engineering students, a need resulting from changes in practice that have occurred over the last two decades. One such change concerns how the disciplines interact. The interaction of the past was stratified: individual disciplines would each perform their tasks in an in-line process. In an in-line process the architect completes his or her design and passes it along to the engineers; the engineers complete their designs and pass those along to the contractor. In contrast, a more typical interaction today brings the disciplines together to work together as team, often from the beginning of the project. One of the common practices that reflects this interaction is the design-build process, a team effort that requires the need to build relationships for success in the industry. This need to build relationships increases the importance of communication and writing effectively; therefore, high-quality writing as a professional requirement became a guiding principle of the new graduate course. When developing the course, strategies for how engineers communicate in industry and what kinds of writing are characteristic of industry were used to shape the content.
The masters program at Cal Poly is required to have a thesis or project document. An exam option is not approved at this time for this discipline. Therefore, the final master's degree requirement of the thesis project and document created the context and guidelines for developing a course that combines both engineering and writing practice in service of the deliverable at its end: the thesis proposal. The course provides an immersion in graduate and professional writing while allowing students to select, focus, and begin to explore a thesis topic, continue to nurture their connections in industry, and submit a polished thesis proposal for approval by advisors.

\section{General Issues for Course Development}

Following the guideline of industry communication and thesis proposal creation helped faculty identify issues for course development. In addition, an assessment of the abilities of incoming graduate students was necessary. In terms of writing skills, some of these general issues follow:

- Writing well for industry

- Communication in developing relationships

- Establishing need and credibility for the thesis project and for the thesis document

- Understanding the thesis process as a method of problem solving

- Communicating for clear contribution to the profession

- Recognition of the writing skills of engineering students are NOT emphasized over the undergraduate career

- Bringing students rapidly up to the appropriate level of writing, given that they enroll in only one or two formal writing courses throughout the undergraduate career

- $\quad$ Re-thinking the common practice that most engineering courses do not demand writing quality (that is, the grade in the course is not influenced by the student's performance in writing)

\section{General Solutions to Issues for Course Development}

Based on these contexts and concerns, ARCE developed a course in Research Methods and Engineering English (ARCE 598) which features several unique components:

- Selection, narrowing, and refining of thesis topic

- Initial conversations with industry partners

- Skills necessary for preliminary topic research

- Writing skills appropriate to the field in a variety of contexts and with a variety of rhetorical strategies (email, correspondence, presentations, literature reviews for the upcoming thesis, and so on)

- Industry discussion in roundtable form of communication skills and requirements

- Creation of a fully developed thesis proposal leading to approval of the student's topic and project

The general solutions to the issues were to involve English faculty and engineering faculty throughout the development and teaching of the course. Specifically the 
engineering faculty would assure proper content in the writing, as well as give input to the dynamics of relationships in industry and within a typical office, while the English faculty (technical communications specialists) would assure the development of writing quality, as well as bring experience in technical writing (in comparison to more literary forms of writing), the common discourse of the engineering profession.

One key innovation of the course is its use of best practices from Writing in the Disciplines. These include well-known strategies such as giving assignments specifically requiring writing that is assessed for its successful communication in addition to its content, providing rubrics for document assessment, and analyzing writing specimens. Most relevant for ARCE 598, however, is the idea of audience: Every communication task undertaken by students is assigned with a specific real-world audience in mind - the thesis advisor, the industry partner, the workplace colleagues, or the grant committee, for example. To prepare to complete a thesis proposal, students undertake a variety of written and oral assignments that may not become part of the proposal itself but rather inform the effective communication strategies that will lead to a successful proposal and prepare the student for graduatelevel and professional writing. A few of these tasks, which mix academic and workplace writing, include

- Memoranda

- Professional emails

- Bibliographic annotations

- Letters of transmittal

- Early drafts of the proposal itself

- Professional presentations

All of these tasks are driven by the student's chosen thesis topic, his or her advisors and industry partners, the requirements of the school, and the forming of a community of colleagues among the class members, who are taught to contribute their own relevant feedback on completed work.

A second key innovation of the course, in addition to its adoption of best practices from Writing in the Disciplines, is the nature of its collaborative processes. Course content emphasizes the relationships not only among academic processes (that is, between experimentation and communication, for example) but also among disciplines (English and engineering) and among populations (between students and industry and between the University and industry, for example).

Industry investment in the course occurs in two forms: partnerships with the students on their projects and round table discussions in the classroom setting. At the start of each quarter, students are given the opportunity to work with an industry partner either by selecting a thesis topic that a firm has offered, or by coming up with a topic on their own and then selecting an industry partner who can assist them in their goals. These industry contacts participate on the students' Master's committees alongside the Cal Poly faculty advisors.
While not all students collaborate with industry for their projects, they do all get the chance to network with professionals working in the field. Each year guest speakers come in to share their experiences in a round table discussion. Surveyors, construction managers, architects, landscape architects, civil engineers, and city council members have all contributed to these discussions. The rapid advances in communication strategies (email, texting, telecommunication) make this discussion different every year. Despite these rapid changes, industry professionals continue to underscore the need for clear communication, thereby increasing students' buy-in to the key concern that effective writing is not a luxury but a necessity if they are to succeed in the field.

To encourage critical thinking about industry relationships in practical ways, the course requires students to ground all of their research within its contribution to academia and industry and to communicate effectively about their discoveries and the relevance of those discoveries. Beginning with the earliest forays into topic selection, and moving throughout the literature review, research, and drafting processes, application and pragmatic value are part of the yardstick against which students' choices are measured.

Perhaps the most unusual innovation of this course, however, is its collaborative use of engineering and English faculty. The course is team taught through the Architectural Engineering Department, with the English faculty member a fully vested participant-not, as is so often the case in these kinds of "collaborations" - a glorified grader. Both faculty members are present in the classroom and work together to teach the course content and to make certain that the students understand the importance of integrating technical knowledge with effective communication. Both faculty members respond and assign grades to all student work. Both help to create a community of colleagues in which questions and comments are seen not as threats to a student's ego but rather as instruments for generating better-quality overall work.

This collaborative model generates a classroom environment in which research and writing are seen not as separate, disconnected entities, but as two sides of a larger process. Students and faculty alike develop an outlook similar to that described by Patton in her University of Missouri case study, in which one civil engineering faculty member in a Writing Intensive course came to see "that the teaching of writing is closely linked to mentoring research, that they are two sides of a discovery process that does not result in simple right answers" [4]. ARCE 598 takes this idea of linked processes and models them not only in the classroom environment but also in the working out of relationships among the interdisciplinary faculty, the students, and the industry partners to create what Patton calls an "[e]culturation into engineering-related writing practices" [4]. At Cal Poly, this enculturation, with its direct inclusion of industry, permits all of the stakeholders in the academic 
and professional processes to be part of the conversation that helps to change graduate students into engineers.

The close collaboration of the English and engineering faculty also allows the course to go beyond a simple multidisciplinary model as defined by Park and Son [5]. They question the value of a multidisciplinary class as merely an "array of numerous topics" presented in a parallel or sequential fashion rather than a true synthesis which draws on the strengths of each discipline to produce a superior final product, as we see in ARCE 598.

Finally, the course uses its preliminary work in research and communication to lead to a fully developed thesis proposal that emphasizes the quality of the thesis project itself, in terms of its research, its analysis and synthesis of that research, and the communication of the research results. This work is discussed in the following section.

\section{Development of Thesis Process}

The experience from the course to date shows that $\mathrm{Cal}$ Poly's new graduate students are not always prepared for the rigors of graduate study. In their undergraduate classes they are accustomed to looking to their professors for assignment directions, due dates, and study and research schedules. In the ARCE graduate program, students are now directed to ask the same goal-driven questions of themselves: "What information do I want to communicate?"; "To whom do I want to communicate?"; "How do I want to communicate the information?"; "When shall I communicate?" and "How will I know if my communication has been effective?"

The students are responsible for the content and quality of their theses. This uncharted water of personal responsibility and freedom of thought and expression has proven to be unsettling to most students. In an effort to the ease the student into the new world of graduate studies the thesis process was divided into manageable sub-goals:

- Choose and narrow the topic and purpose

- Write the prospectus, or need statement

- Form the need statement through guided research and research guided by the need statement

- Write a literature review based on parameters set by the need statement and through fulfilled research

- Convey a budget and schedule

- Assemble the above components into a thesis proposal

- Present the proposal to faculty and students in the ARCE Department

\section{Choose Topic - Industry and Student Collaboration}

The ARCE masters program at Cal Poly encourages the students to select a thesis topic of interest to industry. To help assure industry interest, the student can team up with industry partners on a thesis topic. During the first week of the course, industry partners and their topics are presented to the students. In addition, faculty research interests are also presented. The students' assignment is to pick a topic. The student shows accountability by submitting summaries of discussions (two minimum) with industry and/or faculty in memo form. The audience for the memo is to be a supervisor who is unfamiliar with the topic but is well versed in engineering concepts and lingo. Faculty with professional experience add important depth and credibility in rendering student feedback. The memos are graded on clarity and completeness of content conveyed, appropriateness for the selected audience, and standard English spelling, grammar, and punctuation.

It is common throughout the course for the students to omit important pieces of information in their communications, due to the widespread undergraduate practice of writing only for themselves and not for a specific audience. The ability to write "outside" their own frame of reference is a skill/ability that requires constant repetition. By providing a real-world audience for every writing artifact in the course, ARCE 598 helps students discover and practice the professional skill of writing to a set of standards that are provided externally and not open to negotiation, as well as the professional skill of thinking critically about a project in the short- and long-term based on the needs that created that project.

\section{Prospectus or Need Statement - English and Engineering Collaboration}

Identifying the audience and establishing the need is the emphasis for the prospectus. The audience varies based on topic (i.e. architect, engineer, owner). The prospectus shows the value of the proposed research topic for the proposed audience. Establishing the need is an exercise in the old dilemma of the chicken or the egg. The student is to establish and outline the need for the proposed topic based on research. The choice of research, of course, is determined by the need. However, the research also unveils a need in turn; thus, the claim to a need is directed by the research. Students are often surprised at the non-linear nature of this process.

Annotated bibliographies are introduced and assigned as a means of establishing the need statement. Instruction, grading, and feedback by both English and engineering faculty is critical. The engineering faculty is required for the content and the English faculty for the quality, although the model of collaboration followed in this course encourages indeed demands - some overlap. While an English faculty member, for example, may not be able to evaluate whether or not an equation has been appropriately selected and applied, that faculty member is nevertheless qualified to ask content-driven questions such as how an experiment contributes to the field, how the results might be used in industry, or whether some part of the research process has been under- or un-addressed. Similarly, engineering faculty, although not writing experts, are certainly qualified to respond to technical documents as competent readers of those documents, noting places in which the writing is unclear, for example, or needs development, or contains errors that make reading difficult. Both groups of faculty, 
therefore, responding as readers in a professional community, contribute to quality of content and of writing, a key innovation of ARCE 598.

The expectations for students' writing quality and material content are being set with these early assignments. The students are given multiple assignments (and feedback from instructors) in annotated bibliographies which not only help them to develop the need statement, but also form the first steps in writing the literature review.

\section{Literature Search - Student \& Faculty Collaboration}

Once the need is established and a number of articles in support of the need have been found, a fully developed literature search is written in combination with an introduction and/or background. The typical student has had minimum exposure in developing a literature search. When writing this literature review, most of the students try to use all of the sources identified in their annotated bibliographies. A common challenge lies in guiding the students to show how all of the sources they discuss are related to their newly developed topic and purpose, or, if they cannot establish the connection, to abandon the source. The effort requires presence of both English and engineering faculty working in collaboration (iterative) with the students. In-class peer review sessions with oversight from faculty are the main accountability and assessment tool.

The introduction/background and literature search is the majority of the writing for the thesis proposal. Narrowing the scope of the project is one of the hardest issues for the students to grasp. The peer review sessions have proven to be effective in this task of refining and narrowing the scope, because students often think with more clarity and detachment about their colleagues' projects than they do about their own.

\section{$I V$. Budget and Schedule - Student and Faculty Collaboration}

The budget and schedule are designed to create buy-in from the student and the advisor, as well as accountability for the process of actually doing the research and writing the thesis. Students arrange meetings with their advisors and then demonstrate their understanding of and accountability to the process by producing meeting minutes. Creating a schedule for completion of research and writing of the thesis allows students to visualize the entire research and writing process, as well as to plan for unexpected problems, whether academic (falling behind in coursework or adapting to changing institutional requirements, for example), industryrelated (loss of the industry partner or delays in obtaining information, for example), or personal. With a clear schedule delineated, the advice of the advisor becomes a valuable means of mitigating these potential problems.

\section{$V$. Thesis Proposal and Presentation - University and} Industry Collaboration
The final piece of the course is an audio-visual presentation of the material in the thesis proposal. Members of the ARCE Department, English Department, ARCE students, and industry representatives comprise the audience. A live question and answer session at the end of each student presentation allows the students to see the strengths and weaknesses of their prospective theses.

In addition, students are given written feedback from their peers and professor, feedback directed at not only the quality of the information presented, but also at the quality of the presentation itself and the effectiveness of the presenter as a communicator. All of this input focuses on preparing the students to launch into the formal thesis writing process that will take place over the following school year.

\section{CONCLUSION}

The goals of this class include getting students started on their theses, getting them to take over responsibility for creating their thesis projects, and teaching them to appreciate and use appropriate communication strategies. By combining the efforts and expertise of faculty members in the seemingly disparate fields of engineering and English with best practices in the field of Writing in the Disciplines and vital industry partnerships, students are enabled to draw on skill sets from a variety of settings. Moreover, and perhaps just as importantly, students are exposed to a realworld modeling of teamwork that uses the skills of all team members in the most effective ways. This collaborative model is directly applicable to the workplace, in which colleagues labor together to realize a common vision. Over the course of the year following ARCE 598, if a student adheres to the schedule proposed, he or she will be able to complete the course of study as well as his or her thesis. Students will also bring a valuable skill set to industry: selfmotivation, strong communication, and the ability to use and communicate rigorous scientific methods. 


\section{REFERENCES}

Dunham, C.W., “English in Engineering Education”, Journal of

Engineering Education, March 1937 Issue.

National Commission on Writing for America's Families, Schools, and Colleges. Writing: A Ticket to Work, or a Ticket Out. September 2004.

Paretti, Marie C., and McNair, Lisa. "Introduction to the Special Issue on Communication in Engineering Curricula: Mapping the Landscape", IEEE Transactions on Professional Communication, Vol 51, No. 3, September 2008, 238-241.

Patton, Martha D. "Beyond WI: Building an Integrated Communication Curriculum in One Department of Civil Engineering", IEEE

Transactions on Professional Communication, Vol 51, No. 3, September 2008, 313-327.

Park, Ji-Yong and Son, Jeong-Bae. "Transitioning Toward Transdisciplinary Learning in a Multidisciplinary Environment", International Journal of Pedagogies \& Learning, Vol 6, No.1, September 2010, p 82(12) 1833-4105. 